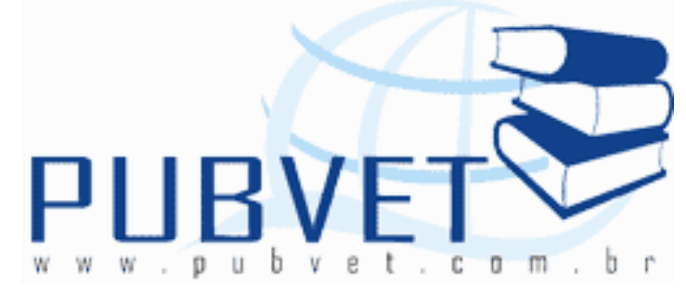

PUBVET, Publicações em Medicina Veterinária e Zootecnia.

Disponível em: <https://doi.org/10.31533/pubvet.v02n12a472.1-7>.

\title{
Corpo estranho linear em gato
}

Lucas A. Gomes ${ }^{1}$, Jakeline P. Zanon ${ }^{2}$, Maria I. M. Martins ${ }^{1}$, Josmari Pirolo ${ }^{1}$, Laurenil Gaste ${ }^{1}$, Rogério A. Marcasso²

${ }^{1}$ Prof. Dr., Departamento de Clínicas Veterinárias, UEL, Londrina-PR ${ }^{2}$ Residente, UEL, Londrina-PR

\section{Resumo}

Corpo estranho linear é mais comum em gatos do que em cães, e na maioria das vezes é emergência cirúrgica. Os sinais clínicos mais comuns são: anorexia, vômito, letargia, dor abdominal e febre. O diagnóstico se dá por meio de inspeção da cavidade oral, na qual se verifica o objeto preso na base da língua. Pode ocorrer plicatura do intestino com dor à palpação abdominal. No exame radiográfico, com ou sem contraste, o sinal mais comum é o pregueamento do intestino delgado. O manejo conservativo em gatos é indicado se os sinais clínicos não justificam o tratamento cirúrgico imediato. Corta-se o objeto linear e verifica-se se ele passará pelos intestinos. Senão, enterotomias múltiplas serão necessárias. Relata-se o caso de um gato macho, siamês, de 9 meses de idade, atendido no Hospital Veterinário da UEL, com vômitos há 36 horas, dor à palpação abdominal. Na inspeção da cavidade oral, foi observado corpo estranho linear preso à base da língua. Ao exame radiográfico abdominal, notou-se acúmulo de gás em alças intestinais. 
Gomes, L.A., Zanon, J.P., Martins, M.I.M. et al. Corpo estranho linear em gato. PUBVET, Londrina, V. 2, N. 50, Art\#472, Dez3, 2008.

Procedeu-se anestesia do paciente e o corpo estranho foi seccionado. Após 12 horas, realizou-se a celiotomia exploratória, inspecionou-se estômago e alças intestinais e nada foi encontrado. No dia seguinte à cirurgia, o animal defecou o corpo estranho linear, evidenciando que em alguns casos, como cita MUIR et al (1995), não há necessidade de cirurgia, e a seç̧ão da linha é suficiente. Assim, conclui-se que em gatos com vômito, corpo estranho linear é um diferencial e nem sempre é necessária intervenção cirúrgica, caso o paciente esteja em bom estado físico.

\section{Linear foreign body in a cat}

\section{Abstract}

Linear foreign bodies are more common in cats than in dogs and often it is a surgery emergency. The most common clinical signs are anorexia, vomiting, lethargy, abdominal pain and fever. Diagnosis relies mainly at the inspection of the oral cavity, in which can be observed the linear foreign body arrested on the region of the base of the tongue. It can cause bowel plication with abdominal pain on palpation. In survey radiographies, with or without contrast, the most common sign is bowel plication. Conservative management in cats is indicated when clinical signs do not warrant immediate surgical treatment. Linear foreign body should be cut and verified if it will passes through the intestines, otherwise, if that not happens, multiple enterotomies will be necessary. We have been reporting a nine-month-old male siamese cat that was examined at the Veterinary Teaching Hospital at Universidade Estadual de Londrina with a story of vomiting for 36 hours and abdominal pain on palpation. In oral examination was observed linear foreign body arrested on the region of lingual frenum. At the abdominal radiography was evident the accumulation of gas in small intestines. Then the patient was anesthetized and the foreign body was cut. After 12 hours was performed a surgical intervention. The stomach and bowel was examined, however, nothing was found altered. One day after surgery, the patient defecated the linear foreign 
Gomes, L.A., Zanon, J.P., Martins, M.I.M. et al. Corpo estranho linear em gato. PUBVET, Londrina, V. 2, N. 50, Art\#472, Dez3, 2008.

body. In that case, like MUIR et al (1995) have been related, the linear foreign body could be eliminated just with the cut of the line procedure, and surgery could not be necessary. Thus in cats with vomit, linear foreign body is an important differential diagnosis and when the patient keeps a good physical condition, surgery not will be always necessary.

\section{Introdução}

Corpo estranho linear (CEL) é mais comum em gatos do que em cães e na maioria das vezes é emergência cirúrgica (Nelson e Couto, 2002). Os CELs mais comumente encontrados são fio dental, linha de costura, cordas, barbantes, meia de nylon e outros tipos de tecido (Santos e Trouillet, 2003). Parte dele usualmente se ancora ao redor da língua na região do frênulo lingual e o restante passa para o intestino, que tenta expulsá-lo por meio de ondas peristálticas, causando pregueamento das alças (Bright e Bauer, 1994; Santos e Trouillet, 2003). Os sinais clínicos mais comuns são anorexia, vômito, letargia, dor abdominal e febre (Bright e Bauer, 1994; Nelson e Couto, 2002; Santos e Trouillet, 2003).

O diagnóstico é dado por meio da inspeção da cavidade oral, na qual se verifica o objeto preso à base da língua e pode ocorrer plicatura do intestino com dor à palpação abdominal (Felts et al., 1984; Bright e Bauer, 1994; Santos e Trouillet, 2003). A região antropilórica é outro local comum de ancoragem do $\mathrm{CEL}$, por isso, não se deve descartar a enfermidade se não localizá-lo na cavidade oral (Santos e Trouillet, 2003). A tração oral ou anal da extremidade livre do CEL é contra-indicada, pois pode resultar em laceração total de mucosa gastrintestinal, formação de estenoses cicatriciais ou ruptura esofágica (Santos e Trouillet, 2003).

No exame radiográfico, com ou sem contraste, a alteração mais comum é o pregueamento do intestino delgado (Felts et al., 1984), contudo, pode-se observar ainda o encurtamento ou dobras intestinais, aumento intraluminal no 
Gomes, L.A., Zanon, J.P., Martins, M.I.M. et al. Corpo estranho linear em gato. PUBVET, Londrina, V. 2, N. 50, Art\#472, Dez3, 2008.

intestino de bolhas gasosas e sinais de peritonite secundários a perfuração (Santos e Trouillet, 2003).

Causa comum de insucesso terapêutico é a não detecção do CEL na base da língua no momento da primeira avaliação clínica (Santos e Trouillet, 2003).

O manejo conservativo em gatos é indicado se os sinais clínicos não justificam o tratamento cirúrgico imediato (Bright e Bauer, 1994; Muir et al., 1995). Corta-se o CEL e se verifica se ele passará pelos intestinos. Se não houver melhora clínica, este pode ter lacerado a parede intestinal, resultando em peritonite bacteriana (Norsmorthy et al., 2004) e assim, usualmente, enterotomias múltiplas serão necessárias (Bright e Bauer, 1994; Nelson e Couto, 2002; Santos e Trouillet, 2003).

O prognóstico é bom desde que o diagnóstico e o tratamento sejam realizados no início da afeç̧ão, evoluindo para reservado a ruim se causar perfurações e peritonite (Santos e Trouillet, 2003).

\section{Relato do Caso}

Relata-se o caso de um gato macho, siamês, de nove meses de idade, atendido no Hospital Veterinário da Universidade Estadual de Londrina, com vômitos há 36 horas e dor à palpação abdominal. Na inspeção da cavidade oral, observou-se um CEL preso à base da língua (Fig. 1). Ao exame radiográfico abdominal, notou-se apenas acúmulo de gás em alças intestinais (Fig. 2). Procedeu-se anestesia do paciente e o CEL foi seccionado (Fig. 3), observando-se imediatamente, laceração da base da língua (Fig. 4). Após 12 horas, realizou-se a celiotomia exploratória, inspecionou-se estômago e alças intestinais e nada foi encontrado. Foi mantido na fluidoterapia com Ringer com Lactato com na taxa de $100 \mathrm{ml} / \mathrm{kg} /$ dia com suplementação com cloreto de potássio a $10 \%$ na dose de $6 \mathrm{ml}$ para cada $500 \mathrm{ml}$ de Ringer com Lactato e Cefalexina injetável na dosagem de $30 \mathrm{mg} / \mathrm{kg}$ via endovenosa a cada 8 horas. Na manhã do dia seguinte à cirurgia (ou seja, 36 horas após a secção da linha) o paciente defecou o CEL (Fig. 5). 
Gomes, L.A., Zanon, J.P., Martins, M.I.M. et al. Corpo estranho linear em gato. PUBVET, Londrina, V. 2, N. 50, Art\#472, Dez3, 2008.

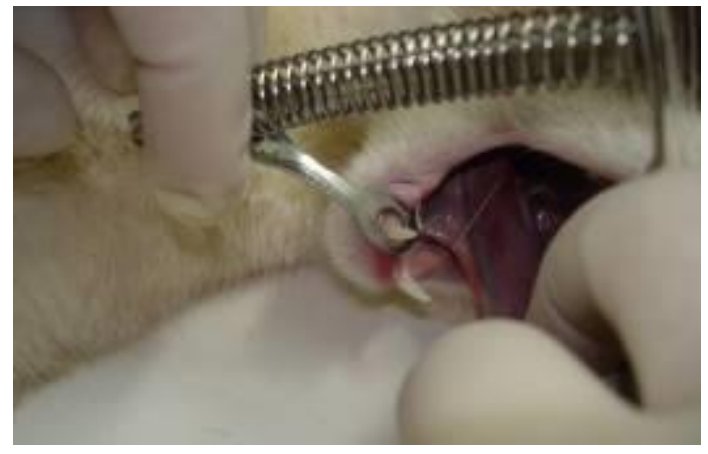

Figura 1: Fotografia da cavidade oral do gato descrito, na qual se observa corpo estranho linear preso à base da língua.

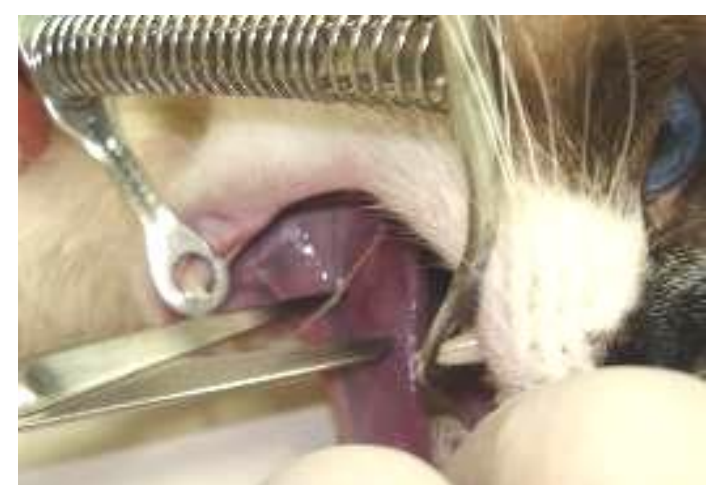

Figura 3: Fotografia da cavidade oral do gato mos trando o momento que o corpo estranho linear foi seccionado.

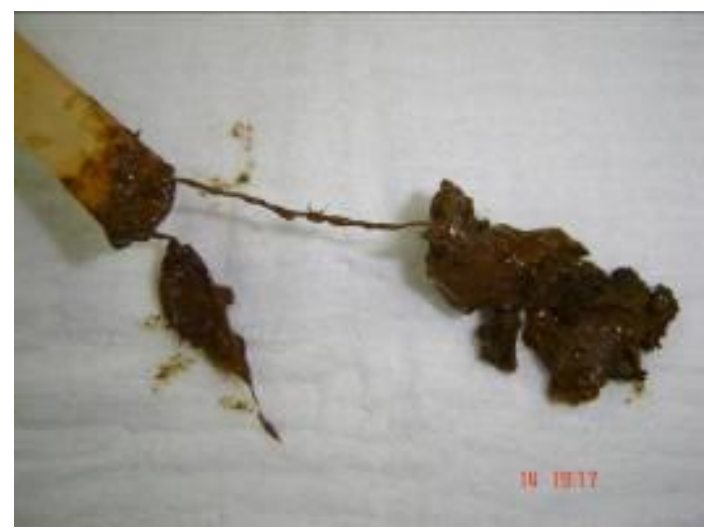

Figura 5: Fezes do animal, onde foi encontrado o corpo estranho linear.

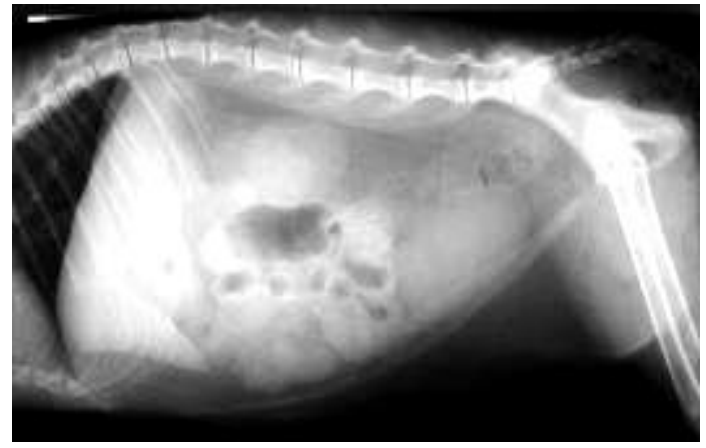

Figura 2: Fotografia da radiografia abdominal do gato, antes da cirurgia, na qual não se observa alterações.

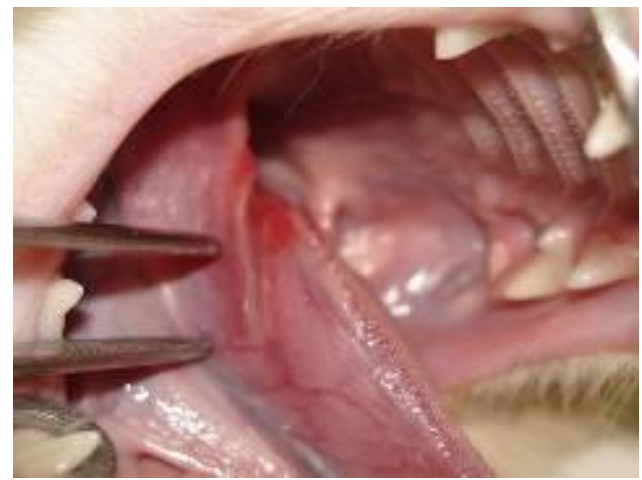

Figura 4: Fotografia da cavidade oral do ga to na qual se pode observar laceração em base da língua após remoção do corpo estra nho linear. 
Gomes, L.A., Zanon, J.P., Martins, M.I.M. et al. Corpo estranho linear em gato. PUBVET, Londrina, V. 2, N. 50, Art\#472, Dez3, 2008.

\section{Discussão}

Gatos com CEL podem necessitar de tratamento cirúrgico de emergência quando não estão bem clinicamente (Bright e Bauer, 1994; Santos e Trouillet, 2003). Todavia, quando estáveis, como no presente relato, pode-se proceder ao tratamento conservativo, seccionando o CEL preso a base da língua e aguardando sua eliminação (Bright e Bauer, 1994; Muir et al., 1995; Orscher \& Rosin, 1998). Deve-se monitorar intensivamente o paciente e mantê-lo internado até a total migração deste pelo trato digestório, sendo esperado no máximo três dias (Santos e Trouillet, 2003).

Apesar de clinicamente bem, foi realizada celitomia exploratória, pois o animal ainda não havia defecado, pois no setor de clínica cirúrgica do Hospital Veterinário este é o procedimento adotado.

$\mathrm{Na}$ exploração por meio da laparotomia, todo o intestino deve ser examinado e realizado a enterotomia no local da obstrução (Orscher \& Rosin, 1998). Como não foi encontrada nenhum segmento obstruído, procedeu-se a celiorrafia.

No dia seguinte à cirurgia, o animal defecou o CEL, evidenciando que em alguns pacientes, como cita MUIR et al (1995), não há necessidade de cirurgia e a secção da linha é suficiente.

Orscher \& Rosin (1998) também relatam estudo no qual nove de 24 gatos, após ingerirem CEL, recebera tratamento conservativo, que consistiu em secção da linha presa na base da língua para liberar o material linear e observação, culminando em pelo trato gastrintestinal, levando de um a três dias. Concluíram nesse mesmo estudo que os sinais radiográficos não contribuíram para a decisão entre o tratamento conservador ou cirúrgico, porém salientam que o retardo na aplicação do tratamento cirúrgico pode resultar em perfuração e peritonite. O paciente aqui relatado defecou o corpo estranho linear 36 horas após a secção da linha, estando em concordância com o que fora relatado pelos autores. Controversamente, Santos e Trouillet (2003) relatam necessidade de intervenção cirúrgica em mais de $90 \%$ dos casos de 
Gomes, L.A., Zanon, J.P., Martins, M.I.M. et al. Corpo estranho linear em gato. PUBVET, Londrina, V. 2, N. 50, Art\#472, Dez3, 2008.

gatos com CEL. Todavia referem à possibilidade de manejo conservador desde que o paciente esteja estável e haja monitoração intensiva.

\section{Conclusão}

Assim, conclui-se que em gatos com vômitos, CEL é um diagnóstico diferencial e nem sempre será necessária a intervenção cirúrgica. Deve-se seccioná-lo e acompanhar a evolução clínica do paciente, reservando o tratamento cirúrgico para os casos que não se evidenciem melhora.

\section{Referências Bibliográficas}

1. BRIGHT, R.M., BAUER, M.S. Chapter 43 Surgery of the Digestive System. In: SHERDING, R.G. The Cat Diseases and Clinical Management.W.B. Saunders Company. $2^{\text {nd }}$ Edition, pp. $1375-1377,1994$.

2. FELTS, J.F., FOX, P.R., BURK, R.L. Thread an sewing needles as gastrointestinal foreign bodies in the cat: a review of 64 cases. JVMA, v.184, p. 56-59, 1984.

3. MUIR, P., ROSIN, E. Failure of de single enterotomy technique to remove a linear intestinal foreign body from a cat. Veterinary Record, v. 136, p. 75, 1995.

4. NELSON, R.W., COUTO, C.G. Medicina Interna de Pequenos Animais, 2 ed. Guanabara Koogan, cap. 33, p. 360-361, 2002.

5. NORSWORTHY, G.D., CRYSTAL M.A., GRACE, S. F., TILLEY, L.P. O Paciente Felino, 2 ed. Manole, cap. 85, p. 370-371, 2004.

6. OSHER, R.J.; ROSIN, E. Capítulo 44 Intestino Delgado. In: SLATTER, D. Manual de Cirurgia de Pequenos Animais. Manole, 2a edição, 1998.

7. SANTOS, A.E., TROUILLET, A.V.P. Capítulo 14 Emergência Gastrintestinal: Corpo Estranho Linear. In: SOUZA, H. J. Coletâneas em Medicina e Cirurgia Felina. Rio de Janeiro. LF Livros de Veterinária, 2003. 